\title{
Bilateral cervical nodal metastasis from unknown primary melanoma: a therapeutic dilemma
}

\author{
Vishwas D Pai ${ }^{1 *}$, Vidhya Manohar ${ }^{2}$, Suvarna Ravindranath ${ }^{2}$ and Sushma V Pai ${ }^{3}$ \\ ${ }^{1}$ Department of Surgical Oncology, Kerudi Cancer Hospital and Research Centre, Bagalkot 587101, Karnataka, India \\ ${ }^{2}$ Department of Pathology, SRL Diagnostics, Bangalore 560076, Karnataka, India \\ ${ }^{3}$ Department of Anesthesia and Critical Care, Kerudi Cancer Hospital and Research Centre, Bagalkot 587101, Karnataka, India
}

\begin{abstract}
Metastatic melanoma with unknown primary [MUP] is a rare presentation. MUP with palpable lymphadenopathy without an identifiable primary or distant metastasis are a subgroup of this rare entity. MUP with nodal involvement most commonly involves axillary lymph nodes followed by inguinal and cervical lymph nodes. Immunohistochemistry (IHC) plays an important role in establishing the diagnosis in these cases. Studies have shown that lymphadenectomy improves survival in these cases. Role of adjuvant radiotherapy as well as chemotherapy remains controversial in view of lack of level 1 evidence. We are presenting a case of MUP involving bilateral submandibular nodes in which one lymph node on each side was completely replaced by melanoma but all other cervical nodes were disease free.
\end{abstract}

\section{Introduction}

Metastatic melanoma with unknown primary [MUP] is a rare disorder accounting for $2-3 \%$ of all cases of melanoma [1]. It comprises of 2 different subtypes with varying presentation and prognosis [2]. First subtype includes those cases which present with palpable lymphadenopathy without an identifiable primary or distant metastasis. Second subtype includes those cases which present with metastatic disease at distant sites without an identifiable primary or palpable lymphadenopathy. Former subgroup is considered as stage III disease whereas the latter subgroup is considered as stage IV disease in the recent AJCC staging [3]. MUP with nodal involvement most commonly involves axillary lymph nodes followed by inguinal and cervical lymph nodes [4]. We are presenting a case of MUP involving bilateral submandibular nodes (level $1 \mathrm{~b}$ ) in which one lymph node on each side was completely replaced by melanoma but all other cervical nodes were disease free.

\section{Case report}

A 60 year old gentleman, a chronic smoker presented with history of bilateral neck swelling of 3 month duration. Right neck swelling appeared before left although patient was not able to recollect exact time gap between the two events. He had not undergone any surgery in the past. Clinical examination revealed $6 \times 4 \mathrm{~cm}$, hard node in right level $1 \mathrm{~b}$ and $4 \times 2 \mathrm{~cm}$, hard node in left level $1 \mathrm{~b}$. Detailed clinical examination didn't reveal any primary tumor in oral cavity or in skin of the scalp or lip. FNAC of both the nodal masses was inconclusive on 2 occasions. Contrast enhanced computed tomography (CECT) neck and thora $\times$ revealed bilateral level $1 \mathrm{~b}$ nodes alone, but no evidence of primary tumor or distant metastases (Figure 1a). Incisional biopsy of the right node revealed presence of clear cells which on IHC was positive for HMB 45 and S100 which confirmed the diagnosis as malignant melanoma (Figure 1b). This stresses the importance of immunohistochemistry (IHC) in establishing diagnosis in these rare cases. In view of the unexpected diagnosis, patient was re examined for any cutaneous or mucosal lesions but in vain. Esophago gastro duodenoscopy and bronchoscopy also didn't reveal any mucosal lesions. Bilateral modified radical neck dissection preserving spinal accessory nerve, sternocleidomastoid muscle and internal jugular vein was performed. Intra and post operative course was uneventful except for left hypoglossal nerve paresis. Histopathological examination confirmed presence of malignant melanoma in both the nodes which were clinically palpable. Interestingly both nodes were completely replaced by metastatic melanoma and all other nodes were free of tumor (Figure 1c). Patient was given the option of adjuvant radiotherapy as well as chemotherapy, but was not willing for the same and hence was kept under close observation. At last follow up, he was disease free with complete recovery of left hypoglossal nerve paresis.

\section{Discussion}

MUP is an interesting phenomenon. Although exact etiology of MUP is unknown, several theories have been proposed. A concurrent, unrecognized melanoma, a previously resected melanoma that was either misdiagnosed or ignored, a spontaneously regressed primary melanoma or de novo malignant transformation of an ectopic nevus cells within a lymph node are some of the explanations [5,6]. Although melanoma arising denovo from the nevus cells in the lymph nodes have been described, immune based regression of the primary tumor

Correspondence to: Vishwas. D. Pai, Department of Surgical Oncology, Kerudi Cancer Hospital and Research Centre, Bagalkot 587101, Karnataka, India, Tel: +91-9449333502; E-mail: vishpai88@gmail.com

Key words: Malignant melanoma, Unknown primary, Nodal metastasis, Melanoma with unknown primary

Received: January 04, 2016; Accepted: February 01, 2016; Published: February 05,2016 


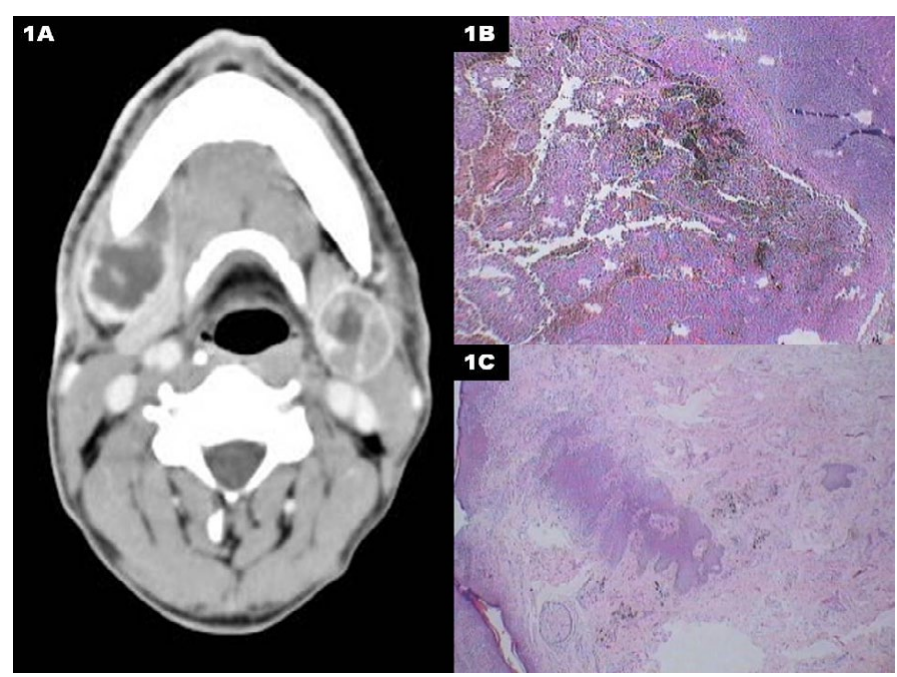

Figure 1. A) CECT neck showing the metastatic bilateral submandibular lymphadenopathy. B) Photomicrograph showing melanin containing cells in the lymph node. C) Photomicrograph shows lymph node replaced by a metastatic tumour, with tumour cells containing dark brown pigment.

is the most favored explanation among the oncologists [7,8]. Although complete regression is very rare, partial regression has been reported in $9-46 \%$ patients $[9,10]$. In the present patient it is very difficult to determine the possible etiology. The fact that entire node was replaced by the melanoma and all other nodes were free does suggest denovo origin of the tumor from the nevus cells in the lymph nodes. However simultaneous malignant transformation in two different groups of lymph nodes is very unusual. Primary drainage area for level $1 b$ nodes includes lower lip, buccal mucosa, lower alveolus, floor of mouth and tongue. Involvement of bilateral nodes is seen in midline tumors and hence possible primary sites are tip of tongue, lower lip and floor of mouth. However non involvement of submental nodes (level 1a) questions the theory of possible midline primary melanoma which regressed spontaneously.

As mentioned previously there are 2 main subtypes of MUP Nodal metastasis of melanoma with unknown primary which are considered as stage III and distant metastasis melanoma with unknown primary which are considered as stage IV [3]. Both these entities vary considerably in terms of management and prognosis [2]. Former subgroup can be treated with surgery with curative intent whereas the latter are treated with varying combination of chemotherapy, targeted therapy and immunotherapy with palliative intent. Five year overall survival (OS) for the former group varies between $39-58 \%$ whereas it varies between $8-18 \%$ for the later group [4,11-13].

Lee et al reported the largest series of nodal metastasis with MUP [4]. They found that median age in this group of patients was $>60$ years and it was more common in males. Axillary nodes were the most commonly involved nodes followed by inguinal and cervical nodes. Studies have shown that lymphadenectomy is quite effective in the management of these cases. The National Cancer Data Base study showed that in patients with MUP, 5 year OS for patients after lymphadenectomy was $55 \%$ whereas without lymphadenectomy was $27 \%$ [14].

Studies have described 5 year overall survival (OS) between 39 $58 \%$ after lymphadenectomy for these patients $[4,11]$. In contrast, 5 year OS after lymphadenectomy for nodal metastasis from known primary melanoma is between $36-40 \%$ (MKP) $[4,15]$. Majority of the studies except the one from National Cancer Data Base study showed superior survival for patients with MUP compared to MKP [14,16,17]. Male gender, older age and multiple nodal involvement are associated with worse outcomes [4].

Role of adjuvant therapy in those who underwent resection is considered debatable. However adjuvant radiotherapy has been found to reduce the risk of lymph node relapse although with no improvement in overall or disease free survival in high risk patients of MKP $[18,19]$. None of the previous studies have specifically looked at the role of adjuvant radiotherapy in patients with MUP and majority of the studies have extrapolated data from the series involving MKP. This needs to be reviewed cautiously after considering the fact that MUP are a subgroup with better prognosis. Hence the role of adjuvant radiotherapy needs to be discussed with the patient after complete lymphadenectomy in cases of MUP.

High dose Interferon for 1 year has been found to improve overall survival in cases of MKP where regional nodes are involved or pathological T stage is T4 [20,21]. A recent trial found biochemotherapy consisting of Dacarbazine, Cisplatin, Vinblastine, Interleukin-2, IFN alfa-2b and granulocyte colony-stimulating factor to be equally efficacious [22]. The latter trial had also included patients with MUP. However none of these studies have specifically looked at the survival advantage with addition of immunotherapy or chemotherapy in patients presenting with MUP. Considering the high toxicity and no clear level 1 evidence, role of adjuvant biochemotherapy needs to be discussed with the patient.

\section{Conclusion}

The purpose of presenting this case is for following reasons

1. Need for IHC to confirm the diagnosis in cases of metastatic neck nodes with unknown primary.

2. Complete lymphadenectomy is the key in achieving cure in these cases.

3. Role of adjuvant chemotherapy as well as radiotherapy needs to be discussed with the patient in light of the absence of level 1 evidence and significant treatment related toxicity.

\section{References}

1. Katz KA, Jonasch E, Hodi FS, Soiffer R, Kwitkiwski K, et al. (2005) Melanoma of unknown primary: experience at Massachusetts General Hospital and Dana-Farber Cancer Institute. Melanoma Res 15: 77-82. [Crossref]

2. De Waal AC, Aben KK, van Rossum MM, Kiemeney LA (2013) Melanoma of unknown primary origin: a population-based study in the Netherlands. Eur J Cancer 49: 676-683.[Crossref]

3. Balch CM, Gershenwald JE, Soong SJ, Thompson JF, Atkins MB, et al. (2009) Final version of 2009 AJCC melanoma staging and classification. J Clin Oncol 27: 61996206.[Crossref]

4. Lee CC, Faries MB, Wanek LA, Morton DL (2008) Improved survival after lymphadenectomy for nodal metastasis from an unknown primary melanoma. $J$ ClinOncol26: 535-541.[Crossref]

5. Giuliano AE, Cochran AJ, Morton DL (1982) Melanoma from unknown primary site and amelanotic melanoma. Semin Oncol 9: 442-447.[Crossref]

6. Anbari KK, Schuchter LM, Bucky LP, Mick R, Synnestvedt M, Guerry D, et al. (1997) Melanoma of unknown primary site: presentation, treatment, and prognosis--a single institution study. University of Pennsylvania Pigmented Lesion Study Group. Cancer 79: 1816-1821.

7. Dasgupta T, Bowden L, Berg JW (1963) Malignant Melanoma of Unknown Primary Origin. Surg Gynecol Obstet 117: 341-345. [Crossref] 
8. McCarthy SW, Palmer AA, Bale PM, Hirst E (1974) Naevus cells in lymph nodes. Pathology 6: 351-358.[Crossref]

9. Blessing K, McLaren KM (1992) Histological regression in primary cutaneous melanoma: recognition, prevalence and significance. Histopathology 20:315-322.

10. Saleh FH, Crotty KA, Hersey P, Menzies SW (2001) Primary melanoma tumour regression associated with an immune response to the tumour-associated antigen melan-A/MART-1. Int J Cancer 94: 551-557. [Crossref]

11. Katz KA, Jonasch E, Hodi FS, Soiffer R, Kwitkiwski K, et al. (2005) Melanoma of unknown primary: experience at Massachusetts General Hospital and Dana-Farber Cancer Institute. Melanoma Res 15: 77-82.[Crossref]

12. Lee CC, Faries MB, Wanek LA, Morton DL (2009) Improved survival for stage IV melanoma from an unknown primary site. J ClinOncol27: 3489-3495.[Crossref]

13. Chang P, Knapper WH (1982) Metastatic melanoma of unknown primary. Cancer 49: 1106-1111.[Crossref]

14. Chang AE, Karnell LH, Menck HR (1998) The National Cancer Data Base report on cutaneous and noncutaneous melanoma: a summary of 8,836 cases from the past decade. The American College of Surgeons Commission on Cancer and the American Cancer Society. Cancer 83: 1664-1678.

15. Schlagenhauff B, Stroebel W, Ellwanger U, Meier F, Zimmermann C, et al. (1997) Metastatic melanoma of unknown primary origin shows prognostic similarities to regional metastatic melanoma: recommendations for initial staging examinations. Cancer 80: 60-65.

16. Wong JH, Cagle LA, Morton DL (1987) surgical treatment of lymph nodes with metastatic melanoma from unknown primary site. Arch Surg 122: 1380-1383.[Crossref]
17. Cormier JN, Xing Y, Feng L, Huang X, Davidson L, et al. (2006) Metastatic melanoma to lymph nodes in patients with unknown primary sites. Cancer 106: 2012-2020. [Crossref]

18. Hamming-Vrieze O, Balm AJ, Heemsbergen WD, Hooft van Huysduynen T, Rasch CR (2009) Regional control of melanoma neck node metastasis after selective neck dissection with or without adjuvant radiotherapy. Arch Otolaryngol Head Neck Surg135: 795-800.[Crossref]

19. Burmeister BH, Henderson MA, Ainslie J, Fisher R, Di Iulio J, et al. (2012) Adjuvant radiotherapy versus observation alone for patients at risk of lymph-node field relapse after therapeutic lymphadenectomy for melanoma: a randomised trial. Lancet Oncol 13: 589-597.[Crossref]

20. Kirkwood JM, Strawderman MH, Ernstoff MS, Smith TJ, Borden EC, et al. (1996) Interferon alfa- $2 \mathrm{~b}$ adjuvant therapy of high-risk resected cutaneous melanoma: the Eastern Cooperative Oncology Group Trial EST 1684. J ClinOncol 14: 7-17.

21. Kirkwood JM, Ibrahim JG, Sosman JA, Sondak VK, Agarwala SS, et al. (2001) High-dose interferon alfa- $2 \mathrm{~b}$ significantly prolongs relapse-free and overall survival compared with the GM2-KLH/QS-21 vaccine in patients with resected stage IIB-III melanoma: results of intergroup trial E1694/S9512/C509801. J Clin Oncol 19: 23702380 .

22. Flaherty LE, Othus M, Atkins MB, Tuthill RJ, Thompson JA, et al. (2014) Southwest Oncology Group S0008: a phase III trial of high-dose interferon Alfa-2b versus cisplatin, vinblastine, and dacarbazine, plus interleukin-2 and interferon in patients with high-risk melanoma--an intergroup study of cancer and leukemia Group B, Children's Oncology Group, Eastern Cooperative Oncology Group, and Southwest Oncology Group. J Clin Oncol 32: 3771-3778.

Copyright: C2016 Pai VD. This is an open-access article distributed under the terms of the Creative Commons Attribution License, which permits unrestricted use, distribution, and reproduction in any medium, provided the original author and source are credited. 